\title{
The new marketing: All media, all of the time
}

Received (in revised form): 12th March, 2001

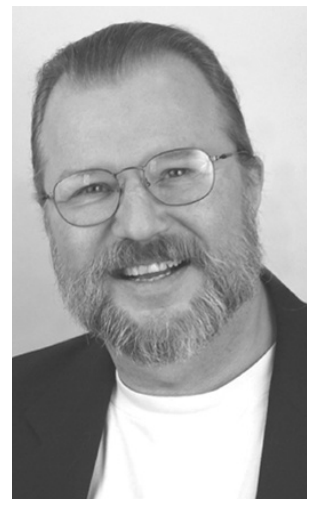

\section{James Morris-Lee}

is president of The Morris-Lee Group, a business-to-business marketing communications firm specialising in the promotion of technology-based products and services. His 25 years in marketing communication have spanned institutional advancement and fund-raising, direct marketing, and business-to-business marketing. He has written more than 50 articles on marketing technologies appearing in the USA in Business Marketing, Corporate Meetings \& Incentives, Direct Marketing, Hospitals, Step-by-Step Graphics, Target Marketing and Medical Meetings, among others, and in the UK in Business Marketing Digest and The Journal of Database Marketing. A contributing author to the Prentice Hall textbook 'Readings in Marketing', his new book, 'Real-time Marketing: New Rules for the New Media', was published in April, 2001 by GATFPress.

Abstract New media integration software tools and print-to-web solutions are allowing deployment of digital marketing content assets in or near real time. Taking best advantage of these new technologies, however, also requires having a full understanding of the inherent strengths and weaknesses of each medium in the media mix. The author reviews those attributes and the roles print and nonprint, volitional and nonvolitional media can play in building response and reinforcing brand identity.

Just a few years ago many people believed that the World Wide Web was going to replace all media, print and nonprint. The result was panic among marketing groups and their advertising agencies and in the boardrooms of many corporations.

To be sure the media world is most certainly not business as usual. A 1999 study by market analysis and research firm the Gartner Group predicted that business-to-business e-commerce would grow from $\$ 145$ bn in 1999 to $\$ 7.29$ trillion in 2004 - fully 7 per cent of the forecast $\$ 105$ trillion in total global sales transactions. ${ }^{1}$

The use of traditional nonprint advertising (network, spot television and radio, cable, and syndication television) is also increasing with cable now representing more than 20 per cent of the total market. In fact, Cape Cod, USA has more dotcom commercials airing on local cable channels than the 2000 Super Bowl. And to the author's eye at least, many of these locally originated spots are infinitely more creative, fun and effective.

Does this mean that print will disappear from the communications landscape? It is unlikely. Advertising pages in all types of publications, both consumer and trade, are up. In fact, in one of its Insider's Reports, Universal McCann, the global media services arm of McCann Erickson Worldwide, raised its predictions of increased advertising spending from 5.5 per cent to 6.8 per cent $(\$ 215 \mathrm{bn})$, with expectations for even more aggressive growth over the next few years. ${ }^{2}$

Direct mail is projected to grow at 4 per cent per year to 2003 , with business-to-business direct mail expanding, according to the Graphic Arts Marketing Information Service (GAMIS), a special industry group of Printing Industries of America, Inc., at a rate much faster than that. ${ }^{3}$ 
An article in the 29th October, 1999, New York Times technology section confirms this. It reported that, 'direct mail is proliferating faster than it did before the Internet, climbing to 44 per cent of all pieces of mail handled last year by the post office from 41 per cent a decade ago and 32 per cent in 1978'. (In fact, the Direct Marketing Association says that 56 per cent of all advertising is now direct-response related.)

Does this mean people are reading more or less? A new study conducted by marketing information company The NPD Group says Americans are reading more (see Table 1). It also showed that as baby boomers enter a stage of life without children, they spend more time reading (a trend that could mean a windfall for publishers). In the past, boomers have affected American culture as they have entered each key life stage, and they are most likely to do so again as they grow older and find more time to read. ${ }^{4}$

NPD Vice President Harry Balzer believes that these data also represent a huge opportunity for marketers. $\mathrm{He}$ adds that what is most interesting about all this is how creative the industry will be in developing the material that people want to read in the format that they most want to read it. Given recent changes in the way Americans are getting their information - not just from books, magazines, and newspapers but also from the Internet - it remains to be seen how each medium will fare, and even more exciting, what new media may be developed.

Is the expansion of Web pages driving the use of multichannel, multimedia advertising to get their sponsoring firms' web-points across? Is the new millennium economy providing the wherewithal for both local retailers and
Table 1: Average daily minutes spent reading by age

\begin{tabular}{ll}
\hline Age & Minutes \\
\hline Under 25 & 24 \\
$25-29$ & 24 \\
$30-34$ & 28 \\
$35-39$ & 31 \\
$40-44$ & 35 \\
$45-49$ & 41 \\
$50-54$ & 44 \\
$55-64$ & 53 \\
\hline
\end{tabular}

major business-to-business marketers to spend more of their dollars on all kinds of advertising, print and nonprint, online and offline?

While the answer to both these questions is a qualified 'yes,' the author does not believe that these dynamics are the real drivers. There is still real value - in the right proportion and given the right strategy - in all media.

Print continues to have an advantage in providing credibility for messages and message sponsors - despite the fact that print is now just as much a digital medium as any purely electronic one. As Yale University webmaster Patrick Lynch points out, information is judged within the context of its origins. Almost without thinking, message recipients instantly ask and answer such questions as: Who is the author? Do I trust the source? How old is the information?

All of this has to do with the 'heaviness' or 'lightness' of a medium a conceptual dichotomy originally conceived by Dan Quah of the London School of Economics (later popularised by Diane Coyle in her book, 'The Weightless World') to describe the dynamics of the digital economy. ${ }^{5}$ When used to define media, these terms have obviously nothing to do with physical weight but the context within which people psychologically place the medium in which a message is bundled in. ${ }^{6}$ (Until the 1980s, the 'balance of trade' literally 
described the physical weight of imports on one side of the scale against the weight of exports on the other. By then, however, computers had become so much smaller and so much more powerful that using weight to declare trade balances became meaningless.) For example, while one may not agree with an author writing, say, in The Independent (for whom Coyle serves as economics editor), the fact that the message came within its pages may itself be sufficient to get a reader to consider it. By comparison, the Web is considered to be 'light' since the computer erodes context as well as provenance and identity.

This is primarily attributable to the fact that on the Web everything with a reasonable level of presentational polish seems to have equal weight, and yet is also somewhat weightless. It is important to note here that as the medium matures this may change. In fact, a study by the Pew Research Center showed that Americans are finding the Internet a more attractive place to get the news in which they are interested. (The online sites of the major national news organisations are also considered, at least among this sample, to be more credible than the news organisations themselves.)

Nonetheless, the research conducted by GAMIS confirms the continuing importance of the role of print in society.

\section{PEOPLE, PAPER AND THE FUTURE OF PRINT $^{7}$}

Key findings of the 1996 GAMIS study, whose research methodology used focus groups followed by an in-depth telephone survey of 1,009 people, underscore the fact that, while technology can seem compelling, it is not the only reason why consumers choose specific media for information. For example, paper-based media are perceived as being:
- people-friendly: print satisfies what these researchers call 'human factors', psychological and sociological. Paper is seen as a convenient and very personal method of communication since it is generally unbound by time or place and available to everyone

- secure: computers are still viewed as somewhat precarious communication devices. They are subject to crashes and documents can be inadvertently deleted, lost or misdirected. Even computerised 'notes' are often seen as being less under the control of the sender

- portable: functionally, print media receive high marks for portability and readability versus computer-mediated communication

- durable: while it is true that notes can get lost, destroyed or misunderstood, paper messages are amazingly durable - important: not only does paper lend messages a sense of importance (and a sense of status to the sender), paper communications also tend to make the receiver feel important, too.

The study also showed that a book or magazine adds a richness of experience not found in electronic media enjoyment that cannot be duplicated by reading the same text on the screen. (As direct marketing maven James $\mathrm{R}$.

Rosenfield succinctly puts it, television is a 'left-hemisphere' medium while the Internet, as with direct mail, is 'right hemisphere'. $)^{8}$

Finally, the study also revealed that, in business organisations, the higher the person's status the more they rely on paper. Interestingly, the senior management people in the GAMIS survey often complained that technology is 'too expensive and that the constant upgrades are needlessly costly in comparison with the benefits derived'. Managers also objected to technological 
Table 2: Advantages and disadvantages of print and electronic media ${ }^{9}$

\begin{tabular}{|c|c|}
\hline Paper and print media & Electronic media \\
\hline $\begin{array}{l}\text { Advantages } \\
\text { - Portability } \\
\text { - Can mark up/edit } \\
\text { - Concrete/tangible } \\
\text { - More comfortable (raised with paper at home and } \\
\text { - Rohool) } \\
\text { - Pomance/intimacy of the written word } \\
\text { Personalisation }\end{array}$ & $\begin{array}{l}\text { Advantages } \\
\text { - Efficiency of finding/accessing information } \\
\text { (browsing function) } \\
\text { - More sensory stimuli (visual, audio, text) } \\
\text { - Compressed storage } \\
\text { - Customisation and manipulation of the written } \\
\text { word } \\
\text { - Management of information/record keeping }\end{array}$ \\
\hline $\begin{array}{l}\text { Disadvantages } \\
\text { - Too cumbersome/storage requirements } \\
\text { - Organisation/management of information } \\
\text { - Difficulty of locating specific information } \\
\text { - Depletion of natural resources (wood); need for } \\
\text { recycling }\end{array}$ & $\begin{array}{l}\text { Disadvantages } \\
\text { - Security (too accessible) } \\
\text { - Not able to hold in hand/intangible } \\
\text { - Fear of losing information } \\
\text { - Inhibits imagination/creative thinking } \\
\text { - Costs } \\
\text { - Physical discomfort (hard on eyes) } \\
\text { - Impersonal } \\
\text { - Need equipment to use }\end{array}$ \\
\hline
\end{tabular}

advances that move faster than necessary, and saw much waste in their systems overall.

Does this mean that print is better than new nonprint media? Not really. According to the study, the use of electronic media within the workplace was valued for searching speed and efficiency based on its multiplicity of resources and volume of information. Conversely, paper and print media were preferred for their readability and portability and its timeliness. (Table 2 compares the advantages and disadvantages of paper and print media with electronic media.)

The point of summarising this research is to show that the Web will not replace other media (in spite of the overzealous claims of most website design firms). The Internet is simply a new star (a new constellation, to be more accurate) on the media horizon. True, the Web contains huge storehouses of information. But even with the best of search engines, it remains a 'Yellow Pages' containing pictures, sound and text — with a cumbersome way of dialling in. In fact, it is acknowledged that most search engines give surfers but a fraction (as little as 16 per cent) of the information that is really available.

\section{THE WEB-TO-PRINT INTERFACE}

Until now, the best attempt at media integration is to use the Web to facilitate print production. And there is now a host of companies that do just that, e-commerce portals such as Noosh, printCaf, PrintNation, Impresse and Collabria. These kinds of sites leverage the World Wide Web as a useful facilitator for delivering both digital and traditional offset print communication to customers and prospective customers in a cheaper, faster time frame. ${ }^{10}$

While there are most certainly great applications for using the Web in this context, what happens when this equation is turned the other way around, literally on its head? What happens if a code could be put at the end of each piece of print communication (or even better, right at the end of the headline in an advert or the item description in a catalogue) to drive traffic from print media directly to an exact page within specific websites at a time when prospective customers can immediately 
actualise (or at least register for later use) their interest?

A number of companies are striving to become the de facto standard for the new magic wand: print-to-web. ${ }^{11}$ It is still a risky game, and the first attempts at transmedia integration (both Wired and Forbes and a number of daily newspapers tested the concept during 2000) showed lacklustre results. Still, product marketers and end users want the kinds of efficiencies true media integration allow. Print-to-web solutions hold a number of other advantages since they:

- reduce the cost of promotion by leveraging each medium in the media mix

- extend the timeliness of printed materials with continually updated information

- connect customers to advertisers more directly, potentially shortening sales timelines with both existing customers and prospects

- help maximise the marketing efficiencies and role each medium can properly serve in the media mix.

Cross-media solutions, however, are nothing new. Before the Internet, the most powerful form of direct response marketing was direct mail followed up with telemarketing. A mailing not only stimulated interest and business in its own right but also provided a reason for telesales people to call. Their calls reminded customers and prospects of the mailing and provided a second opportunity to mail them again if they were interested in an offer but had not received (or had misplaced) a package.

In the recent past, marketers forgot all that. Rather than use the strengths of each medium to reinforce the other in their marketing arsenals, electronic media began to be viewed as a replacement for print. That can be a costly mistake as
Lands' End, the Dodgeville, WI, cataloguer, found out. During the 1999 Christmas season, Lands' End cut back on some of its less profitable catalogues, believing that its rapidly growing online business, coupled with 'more efficient' mailings (a cut of 25 per cent in the number of catalogue pages) would make up the difference. The result was that the company's holiday sales fell 15 per cent from the previous year, forcing them to eliminate 94 jobs. In the process Lands' End discovered something those who practice integrated media marketing have known for years: catalogues do much more than drive phone, mail or Internet sales, they create a connection with customers. For Christmas 2000 Lands' End increased its catalogue circulation by 20 per cent while reinstating the editions it cut the previous year. What was the result of using offline communication to drive online sales? While results are being tabulated, the company witnessed significant spikes in website traffic.

Today, there are really only two types of marketing communication: volitional (information resources actively sought out by product or service buyers) and nonvolitional (uninvited marketing communication which is sent to those same product or service buyers). It is important to keep in mind, however, that much nonvolitional marketing communication is warmly received provided, of course, there is sufficient behavioural data to confirm, with at least some reasonable degree of assurance, that it will be.

The World Wide Web, for example, a volitional medium in which users decide which promotional messages they want to see and read, can also feed the creation of nonvolitional communication whose inherent advantage lies in the fact that it reaches people when they are away from their computers, when their minds are more open and receptive. 


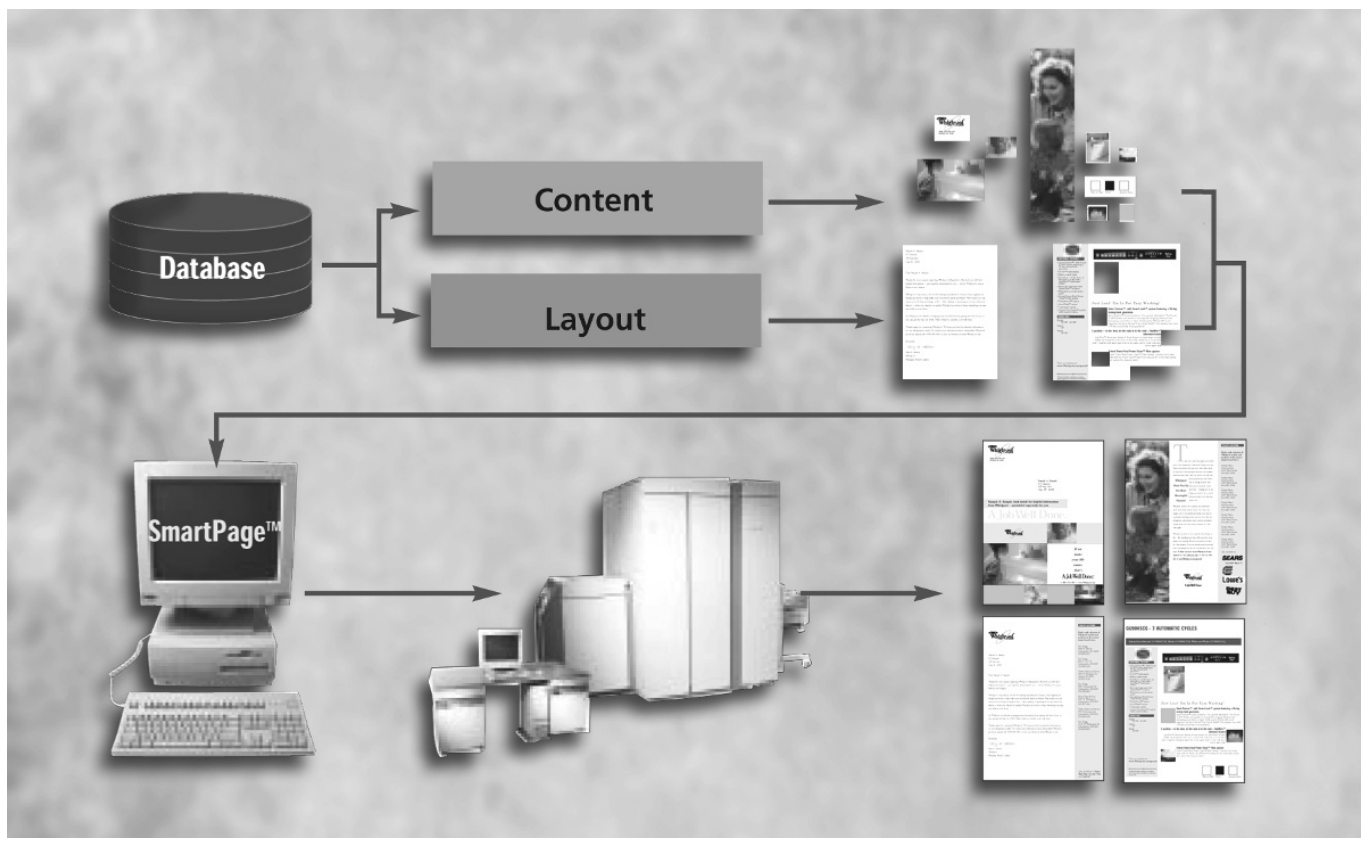

Figure 1: Using real-time electronic media (phone, email), call centre staff at Whirlpool assess customer product interests and needs and instantly deploy direct-mail print communication in the form of minicatalogues that are personalised and customised to each recipient.

After all, what is an e-commerce site anyway? Essentially, it is a collection of text, graphics and purchase-behaviour databases. As interfaces between websites, databases, telesales, document management software, and variable data printing become more seamless, there will be increased use of customised and personalised catalogues, books, CDs and a host of other formats based on a smooth-flowing continuum from Internet to print media. For example, customer relationship management at Whirlpool USA builds on traditional appliance industry newspaper and magazine advertising with a toll-free hotline number offering specific live customer service 24-hours a day. Call centre staff probe for the address where appliances will be used as well as a current mailing address (if different) and also ask how quickly the appliance or appliances will be needed, the model and colour preferences, even family size to help prepare the best-suited recommendation.
Within seconds of the close of a call, those data travel by encrypted packet via the Internet to Vertis Digital Production Services (DPS) in Monroe Township, NJ, USA, the technical architect and print provider for the programme. Each morning, the incoming files from the preceding 24 hours are assembled and personalised print files prepared automatically. Each direct mail piece might comprise four to 12 pages, depending upon customer need. A whole day's production can then be run that same day as a single 'job', sorted in advance to print in zip-code order for immediate mail entry at maximum postal discount (see Figure 1). ${ }^{15}$

At the same time, each medium has its own characteristics and serves a different purpose in the media mix, and information recipients have their own media preferences and informational proclivities. Some of this may be demographic — with younger generations who grow up with 
computers being more interested by sociotechnological conditioning to receive their information in purely electronic form. Much of this phenomenon, however, is psychographic. (There is strong evidence to suggest that personality type is the greatest predictor of how people prefer to send and receive messages.) $)^{12}$ Just as each personality type has its own inherent strengths and weaknesses, so too, each marketing communication medium has built in advantages and disadvantages.

Thus, no single medium can do the work of all of the others. Becoming ready to take advantage of these technologies and media requires an understanding of the specific role each medium can play in the marketing tool kit. Despite the proliferation of media channels in business marketing websites, CD-ROM catalogues, e-mail - most companies view these media as being independent, standalone communication 'events'.

The author began looking at those strengths and weaknesses some years ago and identified them, in collaboration with Scott W. Tilden, as a list of 18 media selection criteria in an article for Business Marketing magazine. ${ }^{13,14}$ The objective was to help marketing managers judge the relative contribution each medium can make towards advertising impact, uncover any hidden media 'biases' in media deployment and thus leverage promotional dollars.

The question as to which media to use and at what relative 'volume' continues to perplex even those fortunate managers whose companies live in a market Valhalla of brisk demand and little or no strong competition. Despite the ubiquity of modern database marketing decision-making tools, all too often companies settle, year after year after year, for the same mix of media.

Those 18 criteria, are still worth reviewing today, with the addition of new media that were not available when the original list of factors was created.

The criteria for media selection are:

1 cost per thousand (CPM): direct mail has a high CPM while fractional page space adverts and direct response cards have a much lower cost per thousand

2 total cost: four colour literature, trade show space, exhibits, travel, entertainment, meals and lodging generally represent significant expenses in a marketing communications budget

3 length of message: of all media, direct mail comes closest to approximating the length of message of a personal sales call

4 completeness of message: here too, direct mail has a decided advantage in telling the whole story about a product or service

5 life of message: the high retention value of some kinds of sales literature gives it a longevity advantage

6 degree of follow-up needed: trade show inquiries, for example, require a greater degree of follow-up than other leads because of the high cost of acquiring them, and because of generally casual, on-the-spot prospect qualification that occurs at shows

7 repetitiveness: space advertising usually requires a great deal of repetition to ensure that the principal target market has been reached enough times for the message to have an effect

8 targetability: direct mail has an advantage because it can be targeted at individual prospects and the message can be customised or personalised to their individual needs

9 dispersion: space advertising has a high degree of dispersion while direct mail can pinpoint individual prospects 10 penetration: the high targetability of 
Table 3: Factors in media evaluation

\begin{tabular}{|c|c|c|c|c|c|c|c|c|}
\hline & \multicolumn{8}{|c|}{ (Rank 1 to 8 for each factor) } \\
\hline & $\begin{array}{l}\text { Public } \\
\text { relations }\end{array}$ & $\begin{array}{l}\text { Space } \\
\text { adverts }\end{array}$ & $\begin{array}{l}\text { Card } \\
\text { decks }\end{array}$ & $\begin{array}{l}\text { Direct } \\
\text { mail }\end{array}$ & Literature & $\begin{array}{l}\text { Trade } \\
\text { shows }\end{array}$ & Internet & CD-ROM \\
\hline $\begin{array}{l}\text { 1. Cost per thousand* } \\
\text { 2. Total cost* } \\
\text { 3. Length of message } \\
\text { 4. Completeness of } \\
\text { message } \\
\text { 5. Life of message } \\
\text { (durability) } \\
\text { 6. Degree of } \\
\text { follow-up* } \\
\text { 7. Repetitiveness } \\
\text { 8. Targetability } \\
\text { 9. Dispersion } \\
\text { 10. Penetration } \\
\text { 11. Demographic } \\
\text { match } \\
\text { 12. Psychographic } \\
\text { match } \\
\text { 13. Ergraphic } \\
\text { (job-function) match } \\
\text { 14. Production } \\
\text { difficulty* } \\
\text { 15. Production cost* } \\
\text { 16. Notice required } \\
\text { 17. Codability } \\
\text { 18. Impact of message } \\
\text { 19. Degree of intrusion } \\
\text { Total } \\
\text { Rank }\end{array}$ & & & & & & & & \\
\hline
\end{tabular}

*Since cost per thousand, total cost, degree of follow-up, production difficulty, production cost and notice required are negative attributes (all others are positive), rank media for these items in reverse order. For example, lowest cost per thousand $=1$, highest $=8$. Lowest total scoring media (rank) satisfy more of the selection criteria.

direct mail makes it a better choice for penetrating key markets

11 demographic match: unless special demographic or geographic editions of business publications are available, direct mail, with its database sorting capabilities, best meets this criterion. (Qualified, opt-in e-mail lists show promise of becoming an alternative as well)

12 psychographic match: direct mail also best satisfies this factor wherever psychographically matched lists are available. But a business publications editorial approach may preselect certain types of readers psychographically as well as demographically
13 ergraphic (job function) match: both direct mail and space adverts in vertical market trade publications deliver a message to prospects in specific job categories

14 production difficulty: because they must function as leave-behind pieces to speak for the product when buyers make their choice, inquiry fulfilment packages justifiably can be elaborate, difficult productions. (Websites, too, often have long production cycles, at least initially)

15 production cost: trade shows, inquiry fulfilment packages, websites and CD-ROM products generally have high production costs compared with other media 
16 notice required: if four-colour photography is involved, product literature generally requires long production lead times. (Digital photography has begun to cut that time)

17 codability: direct mail permits easy encoding of responses by source list, industrial classification, job title, function, etc., for later analysis

18 impact of message: websites and CD-ROMs depending, of course, on their production values can have dramatic impact. Four-colour advertising in large message units can also be a high-impact vehicle.

With the advent of digital media, this list can be extended by adding one more criterion, one that is becoming increasingly critical given the amount of information everyone must process each business day:

19 degree of intrusion: e-mail, for example, is a passive, reactive form of communication. Yet it is perceived as being highly intrusive, especially if there is no existing business relationship. That may change broadcast fax, for example, was once viewed as being highly intrusive, but is perceived as much less so today.

\section{RANKING THE MEDIA}

Although hardly a scientific exercise, ranking the major media commonly employed in business-to-business marketing communication in terms of how well each satisfies the 19 criteria produces a new way of looking at their relative value for a marketing programme.

Table 3 shows a simple matrix for rating each medium by each of these criteria on a one-to-eight scale, allowing the ratings to be summed to determine the unweighted rank of each medium.

Marketing people often find that comparing commonly employed media against one another in a matrix produces unexpected results and hidden media biases in their decision-making behaviour. The purpose of comparing various media, however, is not just to assign a relative value to them. It is simply a device to challenge hidden media-planning assumptions.

Too many companies waste their media communications dollars with too narrow a media focus. Is the budget overly oriented toward print or electronic media? Another way of asking the same question: is the company's Web presence adequately supported with tools that drive traffic and support its identity and brands? Also, is the firm's front-end communication adequately supported with interest fulfilment materials? What relative role should space advertising play? Is the company's trade-show presence, if any, buttressed by direct mail (or e-mail) to ensure return on investment for its involvement?

Ranking media also helps ensure that each medium is employed for the right reasons. Again, the goal is to use media in ways that collectively leverage their individual strengths since no single medium fully satisfies all media selection and deployment criteria.

A careful analysis of the strengths and weaknesses of various advertising media, both electronic and print, should be considered at the very start of the media planning process. Only by balancing a media mix can the true latent synergies among media emerge.

The increasing range of print and electronic digital media creates nearly unlimited marketing opportunities. Yet most companies use and maintain these resources as stand-alone entities - even though much of their content is 
essentially the same. But in an age when windows of opportunity open and close with alarming speed, the need instantly to assess, access and redeploy digital content resources based on a clear understanding of the inherent strengths and weaknesses of each medium is critical.

\section{References}

1 www.gartnerweb.com

2 www.mccann.com

3 GAMIS (Graphic Arts Marketing Information Service) (1996) 'People, paper, and the future of print', Printing Industries of America, Inc.

4 The NPD Group (2000) 'Time lines: How Americans spent their time during the 90s', Port Washington, NY.

5 Coyle, D. (1997) 'The weightless world', MIT Press.

6 Until the 1980s, the 'balance of trade' literally described the physical weight of imports on one side of the scale against the weight of exports on the other. By then, however, computers had become so much smaller and so much more powerful that using weight to declare trade balances became meaningless.

7 GAMIS (1996) op. cit.

8 Rosenfield, J. R. (2000) 'Messages, metaphors and looking for love', Direct Marketing, July, pp. 56-59.

9 Source: GAMIS (1996) op. cit.

10 Raine Consulting Inc. (2000) 'The second wave: Webifying the printing industry'.

11 www.atdots.com, www.barpoint.com, www.digimarc.com, www.digitalconvergence.com, www.gocode.com, www.jumptec.com

12 Mitroff, I. (1983) 'Stakeholders of the organizational mind', Jossey-Bass.

13 Morris-Lee, J. (1987) 'Balancing your media mix', Business Marketing, August, pp. 90-92. (When writing this article the author failed to acknowledge the significant work of Scott W. Tilden, who collaborated with him in identifying media selection criteria and the author is pleased to remedy that omission now.)

14 Morris-Lee, J. (1987) 'Readings in marketing' Prentice Hall.

15 Morris-Lee, J. (2001) 'Real-time marketing', GATF Press, Sewickley, PA. 